\title{
Lung Disorder
}

National Cancer Institute

\section{Source}

National Cancer Institute. Lung Disorder. NCI Thesaurus. Code C3198.

A non-neoplastic or neoplastic disorder affecting the lung. Representative examples of non-neoplastic disorders include chronic obstructive pulmonary disease and pneumonia.

Representative examples of neoplastic disorders include benign processes (e.g.,

respiratory papilloma) and malignant processes (e.g., lung carcinoma and metastatic cancer to the lung). 